\title{
Humanity
}

\section{Finding the humanity: Learning to listen in emergency medicine}

\section{Brianne Budlovsky, BSc. Hon, MD, FRCPC EM*}

I met Audrey ${ }^{1}$ part way through one of my first overnight shifts back from maternity leave. She was a young mother of preschool-aged children, and was dying.

Audrey had breast cancer. Not just breast cancer ugly, metastatic breast cancer that left half of her torso raw and ulcerated and was creating new cannonballs in her skull only 6 weeks after brain surgery. She came in having had a seizure, but was awake, and feeling like herself again (not great, but not seizing). She also was neutropenic and had a fever. Audrey divulged to me that she in fact had the fever on and off for 10 days but had not told anyone because she knew it would mean a hospital admission, one that would pull her away from her family at home.

I presented her case to my staff, outlining the febrile neutropenic orders that I had filled out and that my plan was to call oncology and internal medicine for an admission. It was a slam dunk, as far as I was concerned. My staff, perhaps because she heard the story "from the outside," but most likely because she is far wiser than I, checked me. "Wait a second . . . do we have to admit her? To me, it sounds like this woman is dying, and the last thing she wants is to be in the hospital. Maybe we can find a way to meet her in the middle here. What will give her meaning in her time that is left?"

Audrey had been diagnosed with breast cancer during her youngest child's first few months of life. While breastfeeding, she found a lump. Initially - and for far too long - it was thought to be a blocked duct or mastitis. When the diagnosis was finally made, it had widely metastasized. Her child wasn't even 1 year old.

I had recently read Atul Gawande's book, Being Mortal, and the messages I took to heart came back to me. I stopped thinking about the medicine and about absolute neutrophil counts and duration of fever and which antibiotics to use, and reminded myself that, though she had no control over her illness, we could potentially give her control over her death. For surely this woman knew she was dying - it seemed obvious. Armed with a new sense of purpose and ready to explore her goals of care, I re-entered the room.

Audrey must have been having her own internal battle since I last was in the room telling her that a fever and neutropenia surely required admission. Before I had a chance to launch into the discussion, Audrey started crying.

"Doctor ... I know you aren't an oncologist, but with your experience, can you tell me if I am dying?"

What was this? She didn't know? She was on a privately funded experimental chemotherapy. She had had multiple tumor resections from her brain, multiple rounds of radiation, and a fungating mass comprised $25 \%$ of her chest wall. I was taken aback. I stared blankly. She continued...

"I don't know if it's because I am young . . . or because I have children . . . but no one will just tell me that I am dying. But I'm dying, right? I know I am. Look at me."

I felt disarmed and was unable to approach the conversation in the methodical (but hopefully still tender) way that I had rehearsed in my head. I sat down and took her hand and told her that, although I was no expert on these things, the answer was yes. She was allowed to advocate for the way that she wanted her time to play out. If that wasn't in the hospital, who were we to tell her what to do? We talked about her goals, and those were clearly to be around her kids as much as possible. Thus far, Audrey didn't have a palliative plan. She hadn't put anything into place about how she wanted to die. She told me that it was because no one

From the * Royal Jubilee Hospital, Victoria, BC; Victoria General Hospital, Victoria, BC

${ }^{1}$ Names and details have been changed to protect anonymity.

Correspondence to: Dr. Brianne Budlovsky, Royal Jubilee Hospital, 1952 Bay Street, Victoria, BC, V8R 1J8; Email: bbudlovsky@gmail.com 
had broached the subject with her before, and, although in my heart I hoped that someone had and she just wasn't ready to listen, I also remember that mere moments ago I had been too afraid myself - admission orders in hand, ready to pass the buck.

Eventually, we settled on outpatient antibiotics and close follow-up with her oncologist. I left the room, ran the list with my staff, and prepared to go home. I decided to go and say goodbye to Audrey, to tell her that my shift was done and that I had handed her over. She could sleep and rest as long as she wanted before going back to her own bed. When I went in the room, I sat with her again. Audrey took my hand.

"Doctor, do you have kids?"

All of my plans about using carefully formed, broad statements about quality over quantity, about taking control over her symptoms, about finding meaning within this new (painfully truncated) life she was living, fell to the ground. I started crying, too, and squeaked out a rather undignified, "Yes." Then, not being able to find the words to say, I listened.

Audrey started telling me her fears. She was afraid it would hurt. She was afraid it would be frightening for her kids and her family. She was afraid her children would think she gave up on them. She was afraid that she couldn't mother properly when she was ill. Perhaps the most painful revelation of all was she was afraid that, because her kids were so young, they wouldn't remember her. Here was uncharted territory. I held her hand and cried with her. As a mother, she was living exactly what we all fear most and couldn't escape it.

I wasn't really acting as her doctor at that point anymore, staying after my shift, holding her hand, and crying. But I listened while she told me things she hadn't told anyone before - and that was because I was in a position of incredible honour. She trusted me, because I was a doctor. Or perhaps because I am a mother. Or perhaps both. We talked about options for her death, that it didn't have to be painful or undignified. That she could be at home until the very end if she wanted, with her children and husband around. That she had a choice to stay out of the hospital. That this was her life, and her decision, and also ber death - and that we, as a "medical community," were there to support her as best as we could. Audrey had a palliative care meeting set up before she left the hospital. She thanked me for having the tough conversation with her and said that she had been wanting to get it off of her chest for a long time.

I don't think I did anything that anyone else hadn't tried, but I do think that I was there and willing to listen and to relate at the time that she was finally ready to talk. However, I like to think I made an impact, because I looked her up a few months after. Audrey died 3 weeks later, at home, with her family by her side, and her palliative team in her home to keep her comfortable.

It was a lesson for me, that advocating on behalf of our patients sometimes means letting down our guards, and simply listening. Letting them talk - really talk - so that we can get to the meat of what matters most to them and what scares them the most - by turning off the medical autopilot and not just doing what the febrile neutropenia algorithm tells us to do. By crying with them. By being human.

Keywords: Palliative medicine, humanities, relationship-centered care, end of life care, medical education

Competing interests: None declared. 